\title{
Training Dieters to Eat Intuitively with a Mobile Application
}

\author{
Lauren Outland ${ }^{1}$ \\ ${ }^{1}$ College of Health, Human Services and Nursing, California State University Dominguez Hills
}

\begin{abstract}
Weight loss is commonly recommended to prevent cardiometabolic diseases like hypertension, heart disease, and diabetes. Rather than lead to a long-term healthy weight, dieting can result in weight cycling, which has been shown to be more harmful to health than being overweight. An emerging solution to prevent both excess weight gain and weight cycling is to avoid extremes of hunger and fullness by eating intuitively. Intuitive eating or mindful eating means tuning into interoceptive cues of hunger and fullness to guide when and how much to eat. Mindful eating has been linked to both heart, and metabolic health. It is, however, often labor intensive to retrain chronic dieters to intuitively eat what they need, and nothing more. This study describes a mobile health application that mimics an in-office intuitive eating coaching session. It utilizes homeostasis concepts, and components of the Health Belief Model; including, cues to action, phone prompts, minimal barriers to use, and self-efficacy through repeated immediate feedback. It is expected that this innovation could assist or replace the more labor-intensive in-person methods that exist to train previous dieters to eat intuitively. An enhanced description of this mobile application, the PaleoIntuitive app, is presented in this paper along with a discussion of its expected impact on health behavior.
\end{abstract}

(c) 2018 Californian Journal of Health Promotion. All rights reserved.

Keywords: Intuitive eating, mobile application, cardiometabolic health, cardiometabolic disease

\section{Introduction}

Cardiovascular disease (CVD) and diabetes are leading and increasing causes of morbidity and mortality globally, with sedentary life-styles and excess weight as risk factors (Worel \& Hayman, 2016). While losing weight often reduces risk, it is becoming clear that dieting does not work in the long term. Lifestyle interventions focused on weight loss are often intensive, expensive, and temporary, with most people regaining weight within two to four years (Anderson, Gutierrez, Kennedy, \& Hasty, 2013; Gaesser, Angadi, Sawyer, Tucker, \& Jarrett, 2014; Montani, Schutz, \& Dulloo, 2015). Furthermore, regained weight is often met with repeated bouts of dieting, or weight cycling, which may be more harmful metabolically than simply being overweight, (Montani et al., 2015) as the regained weight is more likely to be visceral (truncal) fat (Al Hannan \& Culligan, 2015; Ouchi, 2016). Visceral fat is especially unhealthy and linked to insulin resistance and inflammation, both precursors of cardiometabolic disease (Al Hannan \& Culligan,
2015; Park, Kwak, Kim, \& Ahima, 2017)). Eating intuitively is a promising and sustainable alternative (Outland, 2010). Eating intuitively is not a diet, but a behavior in which people are aware of their hunger and their satiation.

\section{Homeostasis Applied to Eating Behavior}

Eating intuitively is based on the theory of homeostasis, which, regarding eating, refers to the body's need to monitor and maintain constant and stable energy stores (Marks, 2015). Homeostasis is a condition of living things that involves genetic, hormonal and behavioral feedback loops that are designed to maintain a steady state. The responses to the depletion of stored energy is to increase hunger hormones, create fat cells, and overeat. When an individual responds appropriately to these internally guided cues their hunger is satisfied without overeating, which, in turn, prevents excess weight. Being overly full means that excess calories will likely be stored as fat (Kalra, 2012). Getting too hungry (or dieting) triggers hunger hormones, ghrelin 
and neuropeptide $\mathrm{Y}$, which both act to decrease energy expenditure, increase fat deposition, and result in overeating (Mani \& Zigman, 2017; Müller et al., 2015; Zhang, Cline, \& Gilbert, 2014).

Eating based on interoceptive cues can be learned (Bacon, Stern, Van Loan, \& Keim, 2005; Brevers et al., 2017). However, for the chronic dieter who often has trouble identifying hunger and fullness, it may

require intensive support, practice, and time (Brevers et al., 2017; Humphrey, Clifford, \& Morris, 2015). The support needed for successful transition from the extremes of starving then splurging to eating when hungry often requires help from expensive health professional. Advances in smart phone technology

viable alternative means to learn how to eat mindfully.

\section{The Intuitive Eating Application}

Health Behavior Change through Mobile Applications. Mobile health applications (mHealth apps) that can replicate the therapeutic clinical sessions could quickly reach a large number of chronic dieters at low cost. Their accessibility has led to a surge in the number of health-oriented apps (Schumer, Amadi, \& Joshi, 2018). However, only a few of them have been reviewed by health promotion researchers (Maclean, Higgins, Giles, Sherk, \& Jackman, 2015; Tang, Abraham, Stamp, \& Greaves, 2015). Of those reviewed, one of the criticisms of current health apps is that they are not based in health-behavior theory (Azar et al., 2013; Direito et al., 2014; Maclean et al., 2015). (Azar et al., 2013; Conroy, Yang, \& Maher, 2014; Tang et al., 2015).

Theory Based Functionality. The PaleoIntuitive app is based on the Health Belief Model (HBM), whose features include cues to action, selfefficacy, susceptibility, severity, and reduction of barriers. Users receive a text message on their smart phone, providing both "cues to action" and "reduction of barriers," two constructs critical in the HBM. Upon receiving this text message, users are first prompted to enter how many meals they ate on the previous day. They are then queried about premeal hunger and post meal fullness levels for each meal (see Figures $1 \& 2$ ). After these data are entered, to improve sensitivity of interoceptive cues, users receive four categories of feedback. The first type of feedback is the "diagnosis" that describes the "type of" eater they were that day (from intuitive to nonintuitive), including a pictorial representation of the type of eater (see Figure 3). The diagnosis was designed to create a visceral feeling towards either ignoring hunger cues (starving), or fullness cues (splurging) to evoke a feeling of "susceptibility", another HBM construct. Users also get feedback on the effect this behavior is having on their bodies which can increase both "perceived susceptibility" and "perceived severity", two other constructs in the Health Belief Model. For example, if they have skipped a meal, a page will appear explaining that this causes stomach cells to secrete high levels of the hunger hormone ghrelin. The user is told that high levels of ghrelin cause hyperphagia, slow metabolism, decrease thyroid levels, and stimulate the synthesis of fat cells. This feature underscores the severity of negative health outcomes brought about by going hungry or getting too full (Heppner et al., 2014; Perez-Tilve et al., 2011; Scerif, Goldstone, \& Korbonits, 2011; Poher, Tschop \& Muller, 2018).

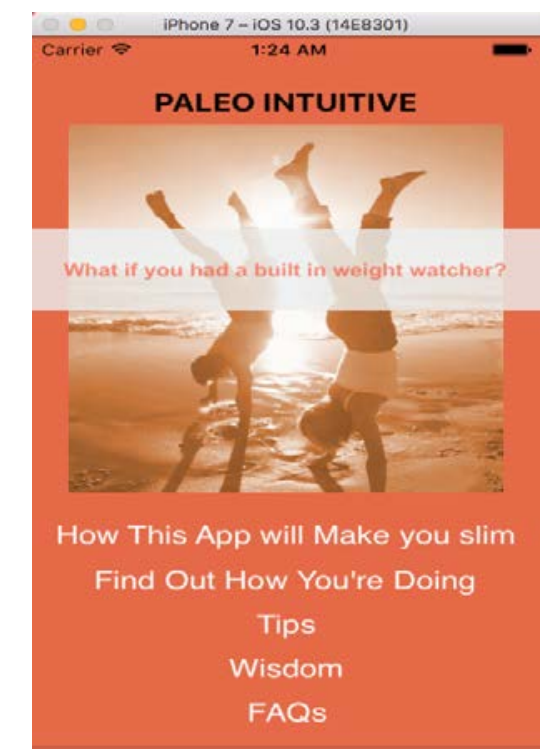

Figure 1. PaleoIntuitive App Menu. 


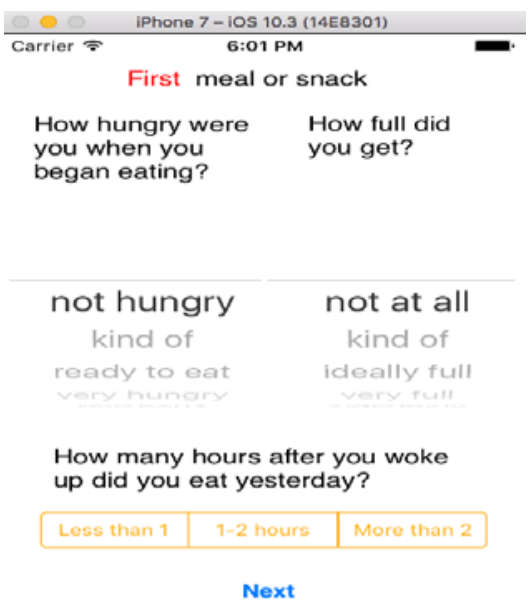

Figure 2. First Meal Assessment of Hunger and Fullness Levels.

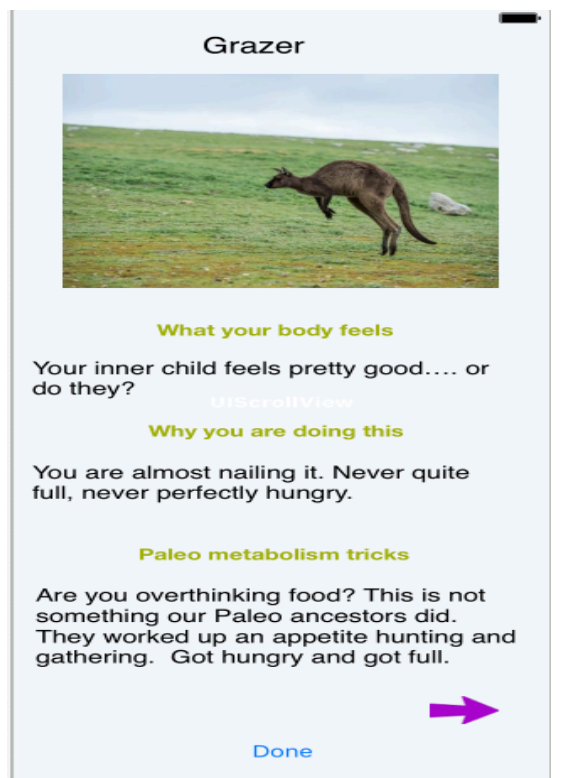

Figure 3. Example of Feedback for a "Grazer."

The more times the user engages in feedback, the better they become at recognizing hunger and fullness, and the better they will get at eating intuitively, leading to sustainable behavior change. Depending on how hungry or full users feel surrounding each meal, typical cues for their behaviors are also part of the feedback, along with the diagnosis, as well as targeted specific tips on how to eat more mindfully by listening to interoceptive cues of hunger and fullness. The implicit and explicit goal of the app is to gain the diagnosis of "Intuitive Eater" a majority of times.
Unlike a diet, this app functions through the creation of sustainable lifestyle changes by teaching the user how to eat.

Application Development. Supported by CSUDH development funds, a virtual "intuitive eating” coaching app was created by the author: an intuitive eating coach and Doctor of Public Health. The overall goal was to help users eat in response to homeostatic cues.

Study Population. To obtain a multi-gender, multi-ethnic sample, with varied income levels, 40 individuals will be recruited through flyers posted on a college campus, as well as in places of worship in Southern California.

\section{Expected Impacts on Users}

Intuitive eating can improve the degree to which an individual can eat based on physiologic cues, maintain or decrease their weight, and positively affect physiological and psychological well-being. Although people already suffering from obesity-related diseases will be motivated to action, the target user of this app is basically anyone who is concerned with their weight. Other studies have assessed the impact of health apps on health outcomes when features linked to behavior change were incorporated into the app (Conroy et al., 2014). It is anticipated that this intuitive eating app will be a more affordable and accessible way to learn how to eat intuitively as compared with in-person classes or coaching sessions. By incorporating the HBM constructs into the design, by acting as a virtual coach, with minimal barriers, using cues to action, and receiving immediate feedback, it is expected to be effective in training individuals to eat intuitively (Bacon \& Aphramor, 2011; Conroy et al., 2014; Ulian et al., 2015; Van Dyke \& Drinkwater, 2014). In a recent review of 26 research papers, cross sectional studies found intuitive eating to be related to healthy weight, healthy eating choices, and healthy eating behaviors (Van Dyke \& Drinkwater, 2014). In prospective studies, eating based on hunger and fullness cues consistently showed improvements in weight maintenance, blood pressure; and cholesterol levels (Van Dyke \& Drinkwater, 2014). These homeostatic-friendly behaviors can substantially 
help individuals improve their health, with less risk of their weight cycling, which often accompanies the "lose weight" recommendation.

As this study is the first of its kind to use an intuitive eating app instead of live session, predictions of the impact it will have on users' eating beliefs and behaviors. is based on this researcher's experience in private practice doing live sessions and replicated in the beta test group with virtual feedback. Drawing from these experiences it is expected that users who have recently stopped dieting might find giving up strict calorie intake difficult, will comprise 20 30\% (10 to 15 participants) However, of those who have not dieted recently, or who gave up dieting altogether, it is expected around a twothirds to three-fourths (30 to 40) will fine intuitive eating a welcome strategy. For those users who continue in the study, it is expected that a majority will be better able to identify hunger and fullness and be able to increasingly eat based on these cues.

\section{Discussion}

While there are many apps available to help decrease caloric intake, most are time consuming due to the need to log in everything consumed on a daily basis; a feature that may decrease their popularity and usage (König, Sproesser, Schupp, \& Renner, 2018). One benefit of the PaleoIntuitive App is that it only takes a user 60 - 90 seconds to log in hunger and fullness for a full day of meals. Also, while there are a few weight loss apps that are grounded in health promotion theory, what makes the PaleoIntuitive app better, in addition to using Health Belief Model constructs, is that it is based on homeostasis (Azar et al., 2013; Litman et al., 2015; Maclean et al., 2015). By having users eat in response to hunger instead of trying to ignore it, excess levels of hunger hormones and the compensatory response that favors weight regain can be avoided. This in turn will make it easier to honor fullness cues and end the meal without overeating.

Intuitive eaters eat when they are hungry, and do not feel obligated to "clean their plate" when they are full. Cultural factors have led us away from this natural state, with diets training us to starve ourselves, and larger portions pressuring us to eat more than we need. The obesity epidemic is so widespread and miss-informed concepts about dieting and healthy eating are so pervasive, that almost everybody could benefit from learning to eat intuitively. A theory-based intuitive eating app has the potential to reach and benefit a great number of people, regardless of weight. Potentially, the PaleoIntuitive app employing key health promotion strategies in training users to eat intuitively could fill a much-needed void in the current effort to promote healthy lifestyle behaviors (Conroy et al., 2014).

To date, there are no other studies on the effects of intuitive eating apps on health or health behavior. Other types of mHealth applications have been found to have significant impact on important health indicators on subpopulations of patients needing to reduce risk factors or improving drug adherence (Chow et al., 2015; Johnston, Bodegard, Jerström, \& Åkesson, n.d.; Wellman et al., 2015) . As mHealth apps with a focus on mindful eating continue to increase as expected, more will be known about their potential impact on population health.

\section{References}

Al Hannan, F., \& Culligan, K. G. (2015). Human resistin and the RELM of Inflammation in diabesity. Diabetology \& Metabolic Syndrome, 7(1), 54. https://doi.org/10.1186/s13098-015-0050-3

Anderson, E. K., Gutierrez, D. A., Kennedy, A., \& Hasty, A. H. (2013). Weight cycling increases T-cell accumulation in adipose tissue and impairs systemic glucose tolerance. Diabetes, 62(9), 31803188. https://doi.org/10.2337/db12-1076

Azar, K. M. J., Lesser, L. I., Laing, B. Y., Stephens, J., Aurora, M. S., Burke, L. E., \& Palaniappan, L. P. (2013). Mobile applications for weight management: Theory-based content analysis. American Journal of Preventive Medicine, 45(5), 583-589. https://doi.org/10.1016/j.amepre.2013.07.005 
Bacon, L., \& Aphramor, L. (2011). Weight science: evaluating the evidence for a paradigm shift. Nutrition Journal, 10(1), 9. https://doi.org/10.1186/1475-2891-10-9

Bacon, L., Stern, J. S., Van Loan, M. D., \& Keim, N. L. (2005). Size acceptance and intuitive eating improve health for obese, female chronic dieters. Journal of the American Dietetic Association, 105(6), 929-936. https://doi.org/10.1016/j.jada.2005.03.011

Brevers, D., Rogiers, A., Defontaine, A., Cheron, G., Clarinval, A. M., Foucart, J., ... Verbanck, P. (2017). Implementation intention for initiating intuitive eating and active embodiment in obese patients using a smartphone application. Frontiers in Psychiatry, 8(NOV), 1-9. https://doi.org/10.3389/fpsyt.2017.00243

Chow, C. K., Redfern, J., Hillis, G. S., Thakkar, J., Santo, K., Hackett, M. L., ... Thiagalingam, A. (2015). Modification in Patients With Coronary Heart Disease, 1255-1263. https://doi.org/10.1001/jama.2015.10945

Conroy, D. E., Yang, C., \& Maher, J. P. (2014). Behavior Change Techniques in Top-Ranked Mobile Apps for Physical Activity. American Journal of Preventive Medicine, 46(6), 649-652. https://doi.org/10.1016/j.amepre.2014.01.010

Direito, A., Pfaeffli Dale, L., Shields, E., Dobson, R., Whittaker, R., \& Maddison, R. (2014). Do physical activity and dietary smartphone applications incorporate evidence-based behaviour change techniques? BMC Public Health, 14(1). https://doi.org/10.1186/1471-2458-14-646

Gaesser, G. A., Angadi, S. S., Sawyer, B. J., Tucker, W. J., \& Jarrett, C. (2014). Exercise and Diet Improve Cardiometabolic Risk in Overweight and Obese Individuals Without Weight Loss. Glucose Intake and Utilization in Pre-Diabetes and Diabetes: Implications for Cardiovascular Disease, (December 2015), 355-367. https://doi.org/10.1016/B978-0-12-800093-9.00029-6

Heppner, K. M., Piechowski, C. L., Müller, A., Ottaway, N., Sisley, S., Smiley, D. L., ... Perez-Tilve, D. (2014). Both acyl and des-acyl ghrelin regulate adiposity and glucose metabolism via central nervous system ghrelin receptors. Diabetes, 63(1), 122-131. https://doi.org/10.2337/db13-0414

Humphrey, L., Clifford, D., \& Morris, M. N. (2015). Health at Every Size College Course Reduces Dieting Behaviors and Improves Intuitive Eating, Body Esteem, and Anti-Fat Attitudes. Journal of Nutrition Education and Behavior, 47(4), 354-360.e1. https://doi.org/10.1016/j.jneb.2015.01.008

Johnston, N., Bodegard, J., Jerström, S., \& Åkesson, J. (n.d.). Effects of interactive patient smartphone support app on drug adherence and lifestyle changes in myocardial infarction patients : A randomized study. American Heart Journal, 178, 85-94. https://doi.org/10.1016/j.ahj.2016.05.005

Kalra, S. P. (2012). A case for new therapy for diabetes, is it leptin? Indian J Endocrinol Metab, 16(Suppl 3), S525-8. https://doi.org/10.4103/2230-8210.105566

König, L. M., Sproesser, G., Schupp, H. T., \& Renner, B. (2018). Describing the Process of Adopting Nutrition and Fitness Apps: Behavior Stage Model Approach Corresponding Author :, 6. https://doi.org/10.2196/mhealth.8261

Maclean, P. S., Higgins, J. A., Giles, E. D., Sherk, V. D., \& Jackman, M. R. (2015). The role for adipose tissue in weight regain after weight loss. Obesity Reviews, 16(S1), 45-54. https://doi.org/10.1111/obr.12255

Mani, B. K., \& Zigman, J. M. (2017). Ghrelin as a Survival Hormone. Trends in Endocrinology and Metabolism, 28(12), 843-854. https://doi.org/10.1016/j.tem.2017.10.001

Montani, J.-P., Schutz, Y., \& Dulloo, a G. (2015). Dieting and weight cycling as risk factors for cardiometabolic diseases: who is really at risk? Obesity Reviews : An Official Journal of the International Association for the Study of Obesity, 16 Suppl 1(February), 7-18. https://doi.org/10.1111/obr.12251

Müller, T. D., Nogueiras, R., Andermann, M. L., Andrews, Z. B., Anker, S. D., Argente, J., ... Tschöp, M. H. (2015). Ghrelin. Molecular Metabolism, 4(6), 437-460. https://doi.org/10.1016/j.molmet.2015.03.005 
Ouchi, N. (2016). Adipocytokines in Cardiovascular and Metabolic Diseases. Journal of Atherosclerosis and Thrombosis, 23(6), 645-54. https://doi.org/10.5551/jat.34918

Outland, L. (2010). Intuitive eating: a holistic approach to weight control. Holistic Nursing Practice, 24(1), 35-43. https://doi.org/10.1097/HNP.0b013e3181c8e560

Park, H. K., Kwak, M. K., Kim, H. J., \& Ahima, R. S. (2017). Linking resistin, inflammation, and cardiometabolic diseases. Korean Journal of Internal Medicine, 32(2), 239-247. https://doi.org/10.3904/kjim.2016.229

Perez-Tilve, D., Heppner, K., Kirchner, H., Lockie, S. H., Woods, S. C., Smiley, D. L., ... Pfluger, P. (2011). Ghrelin-induced adiposity is independent of orexigenic effects. The FASEB Journal : Official Publication of the Federation of American Societies for Experimental Biology, 25, 28142822. https://doi.org/10.1096/fj.11-183632

Scerif, M., Goldstone, A. P., \& Korbonits, M. (2011). Ghrelin in obesity and endocrine diseases. Molecular and Cellular Endocrinology, 340(1), 15-25. https://doi.org/10.1016/j.mce.2011.02.011

Schumer, H., Amadi, C., \& Joshi, A. (2018). Evaluating the dietary and nutritional apps in the google play store. Healthcare Informatics Research, 24(1), 38-45. https://doi.org/10.4258/hir.2018.24.1.38

Tang, J., Abraham, C., Stamp, E., \& Greaves, C. (2015). How can weight-loss app designers' best engage and support users? A qualitative investigation. British Journal of Health Psychology, 20(1), 151171. https://doi.org/10.1111/bjhp.12114

Ulian, M. D., Benatti, F. B., de Campos-Ferraz, P. L., Roble, O. J., Unsain, R. F., de Morais Sato, P., ... Scagliusi, F. B. (2015). The Effects of a "Health at Every Size((®)"-Based Approach in Obese Women: A Pilot-Trial of the "Health and Wellness in Obesity" Study. Frontiers in Nutrition, 2(October), 34. https://doi.org/10.3389/fnut.2015.00034

Van Dyke, N., \& Drinkwater, E. J. (2014). Relationships between intuitive eating and health indicators: literature review. Public Health Nutrition, 17(8), 1757-66. https://doi.org/10.1017/S1368980013002139

Wellman, M. K., Patterson, Z. R., MacKay, H., Darling, J. E., Mani, B. K., Zigman, J. M., ... Abizaid, A. (2015). Novel Regulator of Acylated Ghrelin, CF801, Reduces Weight Gain, Rebound Feeding after a Fast, and Adiposity in Mice. Frontiers in Endocrinology, 6(September), 144. https://doi.org/10.3389/fendo.2015.00144

Worel, J. N., \& Hayman, L. L. (2016). Preventing Cardiovascular Disease in Patients With Diabetes: New Evidence Informs Changes in Standards of Care. The Journal of Cardiovascular Nursing, 31(3), 198-200. https://doi.org/10.1097/JCN.0000000000000333

Zhang, W., Cline, M. A., \& Gilbert, E. R. (2014). Hypothalamus-adipose tissue crosstalk: Neuropeptide y and the regulation of energy metabolism. Nutrition and Metabolism, 11(1), 1-12.

https://doi.org/10.1186/1743-7075-11-27

Acknowledgements: I wish to acknowledge California State University for providing me with a Sabbatical semester, and the Department of Research and Graduate studies for development funds that enabled me to create the intuitive eating application. I would also like to thank my tireless software coder, Arie Selma for making this project a reality. 


\author{
Author Information \\ Lauren Outland, DrPH, MSN, CNM, WHCNP, MPH, BSN, \\ BA \\ Associate Professor \\ School of Nursing \\ College of Health, Human Services and Nursing \\ California State University Dominguez Hills \\ 1000 E. Victoria St. \\ Carson, CA 90747 \\ 310-394-3868 \\ loutland@csusdh.edu;
}

